\title{
A Question of Substorm Size--How Large Must a Magnetic Disturbance Be Before It Can Be Called a Substorm?*
}

\author{
Gordon RosTOKER \\ Canadian Network for Space Research and Department of Physics, University of Alberta, \\ Edmonton, Alberta, Canada T6G 2 E9
}

(Received September 25, 1992; Revised February 19, 1993)

\begin{abstract}
Despite a long history of substorm studies, there have been few attempts in the past to place a threshold on the size of a magnetic perturbation associated with auroral brightenings which qualifies it as a substorm. Certainly no attempt has been made to specify specific thresholds for the directly driven and expansive phase components of substorm activity. In this comment, I shall address these two questions in an effort bring this problem to the attention of the substorm research community.
\end{abstract}

\section{Introduction}

The study of magnetospheric substorms has often featured a rather qualitative approach to the identification of specific features. This letter addresses the question of how large a magnetic perturbation must be before it can be called a substorm. It is fair to say that, at the present time, there is no accepted threshold which separates a substorm perturbation from a perturbation which does not qualify for the name substorm. There are, however, perceptions of what that threshold should be. Furthermore, one often sees a substorm identified (or its existence denied) by the perturbation in the north-south component of the surface magnetic field alone. In fact, it is necessary to inspect all three components of the perturbation magnetic field before making a pronouncement on the existence or absence of a substorm.

One matter which must be considered before addressing the matter of substorm size is the question of which component of substorm activity one is inquiring about. ROSTOKER et al. (1987) have claimed that there are two distinctly different components of substorm activity. The first of these is the directly driven system, which features the large scale eastward and westward electrojets stretching from near noon across the dusk and dawn meridians (respectively) to near midnight. These electrojets respond rather sluggishly to changes in the interplanetary conditions (cf. CLAUER et al., 1983), taking something of the order of $\sim 2 \mathrm{hr}$ to complete their response to a sudden level shift in the input of energy from the solar wind. The second component of substorm activity involves the concept of storage of energy in the tail with its subsequent impulsive release into the auroral ionosphere in the midnight sector. The signatures of the release mark the expansive phase of a substorm, and the changes involve the formation of the substorm current wedge (cf. MCPHERRON et al., 1973) usually located around midnight. KISABETH and ROSTOKER (1974) and WIENS and ROSTOKER (1975) have shown that the expansive phase develops as a series of impulsive activations. The lifetime of each activation is considerably shorter than the response time of the directly driven system (each intensification lasting a matter of $\sim 10-20 \mathrm{~min}$.). Thus, when asking how large a perturbation must be before it can qualify as a substorm, one must first ask if it is the directly driven system or the expansive phase wedge which is being considered. If it is the expansive phase, one must then ask if it is the size of the entire ensemble of current systems (associated with the series of intensifications) or just one of the intensifications that is being considered. With these questions in mind, I shall now address the question of substorm size.

*Portions of this paper have been presented at the Fourth Solar-Terrestrial Prediction Workshop held in Ottawa, May 18 $22,1992$. 


\section{The Components of Substorm Activity}

\subsection{The directly driven system}

It is my opinion that there is no particular lower limit to the electrojet strength associated with directly driven activity. Since there is always a viscous interaction in progress at the magnetopause flanks, where the low latitude boundary layer is formed, there is always a cross-polar cap potential drop of $\sim 10-20 \mathrm{kV}$ at the lowest levels of activity (cf. WYGANT et al., 1983). Thus, there is always an electric field to drive the directly driven electrojets, and the electrojet strength then depends on the magnitude of the ionospheric conductivity. There is almost always some conductivity due to solar radiation, and thus there is always some level of directly driven activity. Thus, it is not possible to define a meaningful lower threshold to the directly driven component of substorm activity.

There is probably some upper limit to the strength of the directly driven electrojets, regulated by a combination of $\boldsymbol{E}$ and the height-integrated Hall and Pedersen conductivities. Certainly, polarization fields can serve to reduce the total $\boldsymbol{E}$ field in a highly conducting region such as an auroral arc. How that transpires depends on the available current, and current limiting instabilities also probably play a role. Based on past observations, the upper limit of perturbations due to the directly driven electrojets is certainly in excess of $\sim 1000 \mathrm{nT}$. The largest perturbations of the surface magnetic field in the historical records are $\sim 5000 \mathrm{nT}$ (although this includes perturbations due to other sources than the directly driven system, such as expansive phase currents, the ring current and dayside DPY currents). Whether the directly driven electrojets can grow to be even larger if solar wind conditions exceed their presently observed extrema, or whether limiting processes prevent the electrojets from exceeding some threshold in terms of current carrying capability regardless of how extreme solar wind conditions become, is an unanswered question.

\subsection{The expansive phase}

In addressing the question of thresholds for the identification of expansive phase activity, one must first decide which regions of the nightside auroral oval become activated during this particular component of the substorm. There seems to be little doubt that an equivalent current of the form shown in Fig. 1 develops in the midnight sector during the expansive phase, and may spread to occupy a broad range of longitudes up to several times zones in extent for large events. There are, however, several different concepts for where the closure currents are found in the nightside magnetosphere and comments on the size of the expansive phase magnetic perturbations must, to some extent, be couched in the context of the disparate views on the magnetospheric closure currents of the wedge. It is possible to model the wedge as the sum of an ensemble of "wedgelets" which evolve along the region of electric field gradient found across the high latitude convection reversal. Figure 2 shows an example of the magnetic perturbation of such a "wedgelet" in this region of space, which occurred in conjunction with the evolution of a typical substorm surge form (cf. Fig. 8 in ROSTOKER (1991) for the corresponding auroral image). Rough modeling of this event using the $H / Z$ ratio of the magnetic field perturbations suggests that this event featured a maximum magnitude of $\sim 250 \mathrm{nT}$ directly under the center of the causative westward electrojet. Studies of substorm expansive phase activity by KAMIDE (1993) suggest that the such substorm expansive phase perturbations have a maximum amplitude of as little as $\sim 100 \mathrm{nT}$. Of course, these disturbances are quite spatially localized (often having a latitudinal extent of less that one degree), and thus observed perturbations are often less than $100 \mathrm{nT}$ and can sometimes be confined to the $Z$-component if the observing station is greater than $\sim 100 \mathrm{~km}$ north or south of the disturbed region. Nonetheless, such disturbances feature all the auroral characteristics of a breakup and also are marked by a pi 2 ULF pulsation (which is yet another marker of an expansive phase onset). It is quite possible to view a substorm expansive phase as the consequence of the sequential activation of a number of such "wedgelets" along the high latitude convection reversal. While the combined signatures may indicate a large current system covering several time zones, the physics of the process is that of the "wedgelets" and not a monolithic wedge of large 


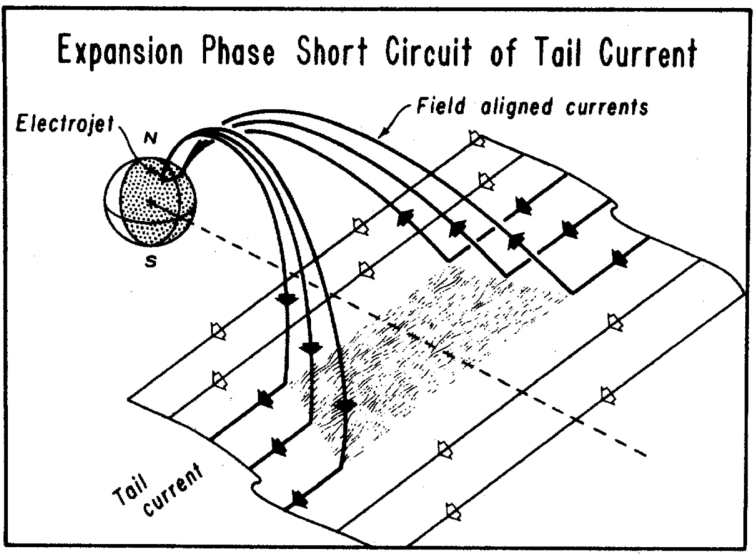

Fig. 1.

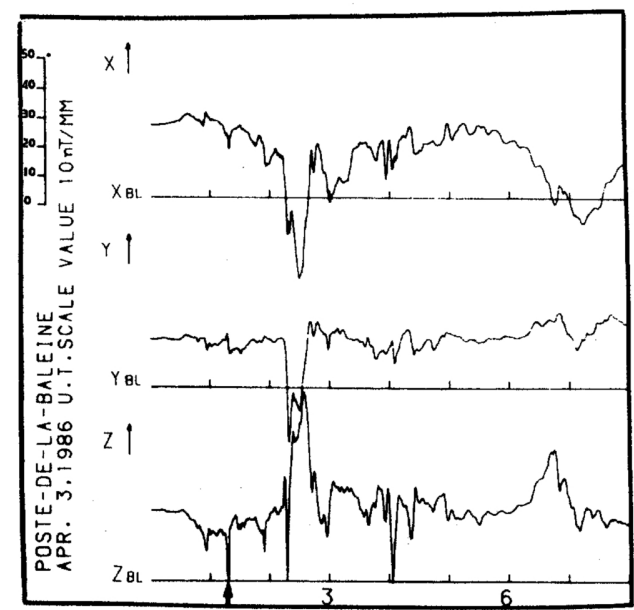

Fig. 2.

Fig. 1. The substorm current wedge (after MCPHERRON et al., 1973). Most researchers, when discussing a substorm, think of this cartoon as representing the only current system involved. In fact, the directly driven system plays an important role in the substorm process and cannot be ignored.

Fig. 2. Magnetogram from the auroral zone station of Poste-de-la-Baleine, showing the magnetic perturbation of a "wedgelet" with onset at $\sim 0115$ UT. If an observatory had existed directly under the narrow westward electrojet responsible for this relatively short lived event, it would have recorded a maximum perturbation of $\sim 250 \mathrm{nT}$ with a lifetime of $\sim 15 \mathrm{~min}$.

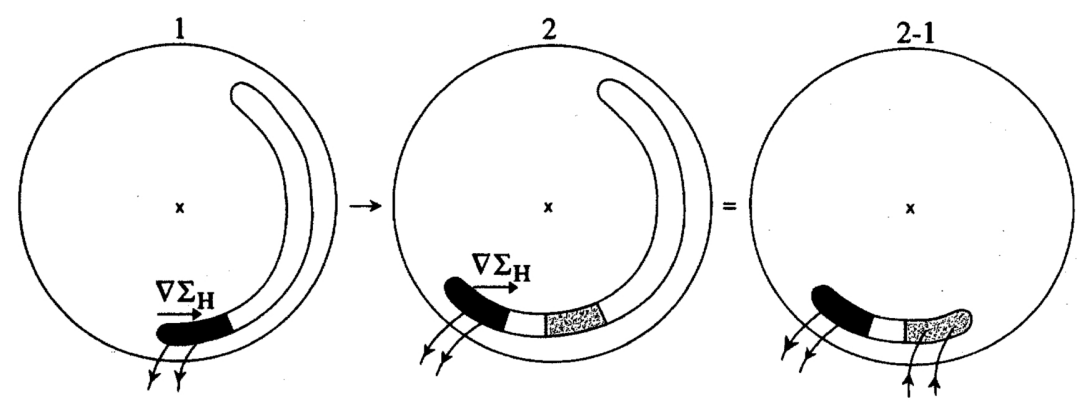

Fig. 3. A possible change in the directly driven system whose equivalent current system is precisely that of the substorm current wedge. The perturbation results from a sudden westward shift of the western edge of the upward field aligned current regeme (after the concept of ROSTOKER, 1974).

spatial scale. The important size criterion is therefore that of the wedgelet (with a threshold size of $<100$ $\mathrm{nT}$ ), and not the wedge itself. The lower threshold of the size of the disturbance would be regulated by the upward field-aligned current density which is required to activate the accelerator region at $\sim 1 \mathrm{Re}$ altitude.

On the other hand, it may well be that the wedge magnetic perturbation comes from a perturbation of the directly driven system, and that the wedgelets described above only contribute localized perturbations within and immediately adjacent to the auroral oval. Figure 3 shows a possible scenario for a change in the directly driven system which could result in magnetic perturbations that could be modeled by the large scale current wedge. This involves the sudden development of a region or energetic electron precipitation over some azimuthal extent causing the azimuthal gradient in Hall conductivity to shift westward. Such a possibility was suggested by ROSTOKER (1974) and the three-dimensional current system involved is shown in Fig. 4 of ROSTOKER (1992). One could imagine such a current reconfiguration to cause the 
development of induction electric field perturbations due to azimuthally localized disruption of crosstail current near the inner edge of the plasma sheet, as proposed by LUI et al. (1992). Since there is no particular threshold to the amount of current that could be shifted azimuthally in such a circumstance, there would be no lower threshold for the size of the wedge based on physical constraints. Any upper limit would be constrained by the size of the directly driven electrojets as discussed earlier in this letter.

\section{Conclusions}

In this letter, I have tried to emphasize that the use of the term "size" to describe a substorm depends on which component of substorm activity one is considering. While there appears to be no particular reason to attribute a lower threshold to the size of the directly driven component (or to perturbations of that driven component associated with shifts in the current carrying region), the lower threshold of "wedgelet" perturbations $(<100 \mathrm{nT})$ may well be determined by the size of the upward field-aligned current density at the westward edge of the "wedgelet".

This research was supported by the Natural Sciences and Engineering Research Council of Canada through the Operating Grant of the author and through a grant to the Canadian Network for Space Research as part of the Network of Centers of Excellence Program funded by the Government of Canada.

\section{REFERENCES}

Clauer, C. R., R. L. MCPherron, and C. SEARLs, Solar wind control of the low-latitude asymmetric magnetic disturbance field, J. Geophys. Res., 88, 2123, 1983.

KAMIDE, Y., A question of substorm size - what controls the dynamic range of substorm intensity?, J. Geomag. Geoelectr., this issue, 1993.

KISABETH, J. L. and G. RostoKeR, The expansive phase of magnetospheric substorms 1. Development of the auroral electrojets and auroral arc configuration during a substorm, J. Geophys. Res., 79, 972, 1974.

Lui, A. T. Y., R. E. Lopez, B. J. Anderson, K. TAkahashi, L. J. Zanetti, R. W. McEntire, T. A. Potemra, D. M. Klumpar, E. M. Greene, and R. Strangeway, Current disruption in the near-earth neutral sheet region, J. Geophys. Res., 97, 1461, 1992.

McPherron, R. L., C. T. Russell, and M. P. Aubry, Satellite studies of magnetospheric substorms on August $15,19689$. Phenomenological model for substorms, J. Geophys. Res., 78, 3131, 1973.

Rostoker, G., Current flow in the magnetosphere during magnetospheric substorms, J. Geophys. Res., 79, $1994,1974$.

Rostoker, G., Some observational constraints for substorm models, in Magnetospheric Substorms, edited by J. R. Kan, T. A. Potemra, T. Iijima, and S. Kokubun, p. 61, Geophys. Monograph 64, Amer. Geophys. U., Washington, 1991.

RosTOKER, G., Mapping of regions of auroral activation in the ionosphere to the magnetotail, in Proceedings of the International Conference on Substorms (ICS-1), ESA SP-335, p. 71, Paris, 1992.

Rostoker, G., S.-I. Akasofu, W. Baumjohann, Y. Kamide, and R. L. McPherron, The roles of direct input of energy from the solar wind and unloading of stored magnetotail energy in driving magnetospheric substorms, Space Sci. Rev., 46, $93,1987$.

WiENS, R. G. and G. Rostoker, Characteristics of the development of the westward electrojet during the expansive phase of magnetospheric substorms, J. Geophys. Res., 80, 2109, 1975.

Wygant, J. R., R. B. TORBerT, and F. S. MOZER, Comparison of S3-3 polar cap potential drops with the interplanetary magnetic field and models of magnetopause reconnection, J. Geophys. Res., 88, 5727, 1983. 